\title{
Adolescents Nutritional Status and its association with Academic Performance in South Ethiopia; a facility-based cross-sectional study
}

Selamawit Woldeyohanes Katiso

Wolaita Sodo University

Amene Abebe Kerbo

Wolaita Sodo University

Samson Kastro Dake ( $\sim$ tasamsona@gmail.com )

Wolaita Sodo University https://orcid.org/0000-0002-7687-4674

Research article

Keywords: Academic performance, Adolescents, Nutritional status, Height for age, BMI for age, Ethiopia

Posted Date: August 20th, 2020

DOI: https://doi.org/10.21203/rs.3.rs-29907/v2

License: (c) (i) This work is licensed under a Creative Commons Attribution 4.0 International License.

Read Full License

Version of Record: A version of this preprint was published at BMC Nutrition on April 29th, 2021. See the published version at https://doi.org/10.1186/s40795-021-00420-8. 


\section{Abstract}

Background: Though evidence about the magnitude of malnutrition is well established in Ethiopia, the evidence is scarce about the association of nutritional status with academic performance among adolescents. Thus, this study aimed at determining the association of nutritional status with academic performance among adolescents attending secondary schools in Wolaita Sodo town, Southern Ethiopia.

Methods: A facility-based cross-sectional study was conducted among 670 systematically selected adolescents in secondary schools of Wolaita Sodo town from April to June 2019. The academic performance of the adolescents was measured using the average mark score of two consecutive semester's results of the overall subjects. Data were analyzed with STATA software Version 15. Descriptive statistics, Pearson Correlation, and linear regression were used in the statistical analysis. A $p$ value $<0.05$ was considered as statistically significant.

Results: The mean academic performance of students was $69.21 \pm 0.42$ (95\% Cl: $68.34 \%-70.02 \%)$. An average mark score of students increased by 1.89 ( $\beta=1.89 ; 95 \% \mathrm{Cl}: 1.14,2.64)$ for a unit increase in BMI for age $z$-score. Being female decreased an average mark score by $2.63(\beta=-2.63 ; 95 \% \mathrm{Cl}:-4.28,-0.98)$ and being from a separated parents decreased by $4.73(\beta=-4.73 ; 95 \% \mathrm{Cl}:-6.73,-2.74)$. An average mark score of students from the lowest wealth class decreased by $9.92(-9.92 ; 95 \% \mathrm{Cl}:-12.79,-7.04)$ as compared to students from the highest wealth class. Attending private schools increased the average mark score of students by $4.18(\beta=4.18 ; 95 \% \mathrm{Cl}: 2.46,5.90)$.

Conclusion: This study has ascertained that poor academic performance was reported among undernourished students, girls, students whose parents were separated, students of low wealth status households, and students enrolled to public schools. Launching nutritional interventions, household income generating activities targeting lowest wealth status households, and giving tutorial classes for female students were recommended.

\section{Background}

Nutritional status is one of the main factors that could affect academic achievement by limiting students' ability to learn (1). Undernutrition can inhibit growth, retards mental development, and reduces motivation and educational attainments (2). Obesity/overweight also has the potential to impair academic performance via social pathways such as discrimination and stigma (3).

One of the vulnerable stages of life is adolescence, where absolute nutrient needs are greater than that in infancy or childhood (4). Undernutrition may increase the risk for poorer cognitive outcomes $(5,6)$. The adolescent stage comprises one-sixth of the world's population; of which over $90 \%$ live in sub-Saharan Africa, and South and Southeast Asia (7). Ensuring that adolescents can successfully pass this phase of life will help to break the cycle of poverty and produce benefits for individuals, communities, and nations (8). 
Despite the economic growth observed in developing countries, undernutrition is still highly prevalent and overnutrition is also becoming a public health concern (9). According to the Global School-Based Student Health Survey, the mean BMI estimates for adolescents in South Asia, Southeast Asia, East Africa, West Africa, and Central Africa were $<20$. The lowest BMls were seen in Ethiopia, Niger, Senegal, India, Bangladesh, Myanmar, and Cambodia (10). On the other hand, globally, $10 \%$ of adolescents are overweight with the prevalence of obesity varying between $2-3 \%$. The prevalence varies from $10 \%$ in Africa and Asia to more than $20 \%$ in the United States of America (USA) and Europe (11).

Students in sub-Saharan African countries have learned less than half of what is expected and according to the World Bank report, students' academic achievement in Ethiopia is also low $(12,13)$. Academic performance might also be affected by other factors like the wealth status of the parents, type of school, parents' educational level, marital status and occupational status (14-17).

Several studies were conducted on the magnitude and risk factors of nutritional status (18-20). However, the association of nutritional status with academic performance among adolescents was inadequately addressed in Ethiopia. Thus, this study aims to assess the association of nutritional status with academic performance among adolescents attending secondary schools in Wolaita Sodo town, South Ethiopia.

\section{Methods}

\section{Study setting}

Wolaita Sodo town is the administrative capital for the Wolaita zonal administration in South Ethiopia located at $380 \mathrm{~km}$ south from Addis Ababa. The town has 3 sub-cities; 11 lower administrative units and the total population is estimated to be 182,$607 ; 49 \%$ were female. Common staple foods in the area are cereals, roots, tubers, and vegetables.

Seven public and two private schools deliver secondary education to the population in the town and the surrounding areas.

\section{Study design and period}

We conducted a facility-based cross-sectional study involving adolescents in secondary schools from April to June in 2019.

\section{Population and sampling}

The source populations were all adolescents in secondary schools in Sodo town and selected adolescents were studied. Pregnant adolescent girls were excluded. A sample size of 670 was calculated with the following assumptions; $95 \%$ confidence level, $5 \%$ margin of error, an estimated magnitude of students' academic performance of $72.8 \%$ taken from a similar study in Ethiopia (21), design effect of 2 and $10 \%$ non-response rate. The schools in the town were stratified into public and private by assuming 
socio-economic differences among the students. Among seven secondary schools (two private and five public) in the town, one private and three public schools were selected randomly. The sample size was allocated to the schools proportional to the number of students enrolled. The list of students enrolled in each school was used as a sampling frame and the study participants were selected using systematic random sampling.

\section{Variables}

\section{Outcome}

The academic performance of the students was an outcome measure. It was measured by totalling students' average mark score of the overall subjects of the last two consecutive semesters.

\section{Exposure variables and covariates}

Socio-economic and socio-demographic: Age, Sex of adolescent, marital status of parents, Education and occupation status of parents, and Wealth status.

Wealth status was generated by using principal component analysis (PCA) and based on the result household wealth index/status was converted into quartiles and categorized as Lowest, Second, Middle, Fourth, and Highest (22).

\section{Nutritional status indices:}

Underweight- is BMI for age $\mathrm{z}$-score (BAZ) of $<-2$ standard deviation (SD) on the WHO growth reference cut-off point (23).

Overweight- was computed with BMI for age z-score (BAZ) of >+1 SD on the WHO growth reference cutoff point (23).

Obesity- was computed with BMI for age z-score (BAZ) of >+2 SD z-score based on the WHO reference cut-off point (23).

Stunting-is the height for age $z$-score (HAZ) of <-2 SD on the WHO growth reference cut-off point (23).

Dietary diversity score: Dietary diversity was determined by using the dietary diversity score (DDS). Three non-consecutive days 24 hour recall of adolescents' consumption of commonly consumed foods in the area was used to collect information for DDS (24). Foods were categorized into 10 groups based on FAO recommendations; (1) starch stable food, (2) vegetables, 3) fruits, (4) meat, (5) egg, (6) fish and other seafood, (7) legumes, nuts and seeds, (8) milk and milk products, (9) oil and fats, (10) sweets, spices, condiments and beverage (25). The response categories were "Yes" if at least one food item in the group was consumed and "No" when a food item in the group was not consumed. The results were summed and classified into $\leq 4$ food items and $>4$ food items (26). 
Behavioral factors: alcohol consumption, the purpose of spending much time on the internet, and being absent for $10 \%$ or more of school days for any reason in a calendar year.

\section{Data collection}

A structured interviewer-administered questionnaire was adopted from relevant articles and related literature (22). The questionnaire was pre-tested on $5 \%$ of the respondents who were later not included in the main study and no adjustments were made after the pre-testing. Four data collectors and two supervisors were trained for two days on different modules of the questionnaire, anthropometric measurement, and ethics.

Anthropometric measurements were standardized against an expert measurer for Technical Error of Measurement (TEM). Weight was measured using a portable digital flat Seca scale (Scale electronic scale, 770 Hamburg). Height was measured by Seca body meter (Seca 274 body meter). All measurements were taken three times, and the average was taken. Academic performance and absenteeism data were taken from school records.

\section{Statistical analysis}

Data was entered on Epi-Data Version 3.1 and analyzed by using Stata Version 15. Anthropometric data were analyzed using the WHO Anthro-plus software version 1.0.4 and compared with WHO reference (27). Frequency, percentage, mean, and standard deviation of the mean were performed for the main variables. Pearson correlation was used to check the relationship between nutritional status and academic performance. We used linear regression analysis to select exposure variables with an association to the outcome. Exposure variables with a $p$-value of less than 0.25 in the bivariate analysis were taken to multivariate linear regression to identify independent predictors for academic performance. A $p$-value < 0.05 was considered for statistical significance and parameter estimates (B) with $95 \%$ Cls were reported.

\section{Results}

\section{Socio-demographic characteristics}

A total of 670 adolescents participated in this study making the response rate $100 \%$. The mean age of the respondents was $16.18 \pm 1.66$. Of the total respondents, 339 (50.60\%) were girls. The majority, 545 (81.34 $\%)$ of the parents were currently married. One hundred eighty-three $(27.31 \%)$ mothers and $318(47.46 \%)$ fathers of the students completed college or university education. More than one third $233(34.78 \%)$ of the mothers were merchants whereas $284(42.39 \%)$ fathers were government employees. As for the wealth index, $158(23.58 \%)$, of study participants were from the fourth class (Table 1 ).

\section{Nutritional status, dietary diversity and behavioural factors}

The overall prevalence of any form of malnutrition was $29.33 \% ; 6.30 \%(95 \% \mathrm{Cl}: 4.5,8.5)$ were underweight, $9.70 \%$ (95\% Cl: $7.6,12.2)$ overweight, $4.11 \%(95 \% \mathrm{Cl}: 2.8,5.7)$ obese, and $9.24 \%(95 \% \mathrm{Cl}: 7.2$, 
11.4) were stunted. Majority 469 (76.37\%) of the adolescents spend their time on the internet for social media and about one-fourth $166(24.78 \%)$ drink alcohol. About 163 (24.33\%) adolescents were absent for $10 \%$ or more of school days in the academic year. More than half $396(59 \%)$ of the adolescents had a dietary diversity score of $\leq 4$ food items (Table 2 ).

\section{Relationship between nutritional status and academic performance}

There is a positive linear relationship between academic achievement and BAZ $(r=0.23)$, and HAZ $(r=0.14)$ (Table 3).

\section{Proportion and predictors of Academic Performance}

The mean academic performance of the students was $69.21 \pm 11$ SD (95\% Cl: $68.38 \%, 70.04 \%)$ out of hundred. Being a girl decreased an average score of academic performance by $2.63(\beta=-2.63 ; 95 \% \mathrm{Cl}$ : $-4.274,-0.981)$. An average mark score of students from separated parents decreased by $4.73(\beta=-4.73 ; 95$ $\% \mathrm{Cl}:-6.73,-2.73)$ as compared to students from married parents. Being from the first-class wealth index decreased an average mark score of students by 9.92 ( $\beta=-9.92 ; 95 \% \mathrm{Cl}:-12.79,-7.04)$. An average mark score of students from a wealth index of second class decreased by $5.66(-5.663 ; 95 \% \mathrm{Cl}:-8.132,-3.194)$ as compared to students from the highest wealth class. Attending private schools increased an average mark score of students by $4.18(\beta=4.18 ; 95 \% \mathrm{Cl}: 2.46,5.90)$ compared to their counterparts. BAZ was positively associated with academic performance. A unit increase in BAZ increased an average mark score of students by $1.89(\beta=1.89 ; 95 \%$ Cl: $1.14,2.64)$ (Table 4).

\section{Discussion}

In this cross-sectional study, the mean academic score of students was $69.21 \pm 11$ (95\% Cl: $68.34 \%$, $70.02 \%)$. This is consistent with a study from Hawa Gelan (Ethiopia) $(67.2 \% \pm 15.4 \%)(28)$. However, it is higher when compared with a study done in Nigeria (53.30 \pm 7.15$)(29)$. A higher mean score was reported from Debre-Tabor (Northern Ethiopia) $(71.65 \pm 12.63)(30)$. This disparity might be explained by the difference in students' assessment techniques, the curriculum, testing, and resource accessibility. Although there exists a national standardized testing, the test is given only for $8^{\text {th }}$ and $12^{\text {th }}$ grades.

There was a statistically significant positive association between nutritional status (BAZ) and academic achievement. This finding agrees with studies from Northern and Southeast Ethiopia, where HAZ was associated with students' academic performance $(30,31)$. Despite the agreement with these studies, the correlation coefficient in our study is low. The possible reason might be the small sample size used in the mentioned studies. This finding is inconsistent with a study conducted in Meskan District in Southern Ethiopia, where there was no statistically significant association between HAZ and academic performance (32). Different to our study, another study conducted in North Ethiopia reported that there was no statistical association between BAZ and academic performance (30). This might be due to differences in sample size or variability of the variables involved in the analysis. 
Consistent with studies conducted in Ethiopia, Kenya and Nigeria, being a girl decreased students' academic performance (33-35). The most possible reason could be the higher workload among girls in the household than boys which could affect their time for study. A different finding was reported from Ghana where the academic achievement of girls was significantly higher than boys (36). This difference might be due to the socio-cultural difference in the study areas.

The findings of the present study indicated that students from separated parents scored significantly lower than those from married parents. This is consistent with studies conducted in Addis Ababa (Ethiopia) and Ghana $(37,38)$. Similarly, another study reported that divorce significantly limited students' academic performance (38). This could be due to psycho-social and financial crises caused by marital instability.

Compared with students from the highest wealth class, being from wealth index first and second classes decreased students' academic performance. This finding is in agreement with studies conducted in Dessie (Northwest Ethiopia) and Hawa Gelan district in Southwest Ethiopia(28, 39). Similarly, another study from Goba town in Ethiopia depicted that a higher wealth index is associated with better mathematics scores (31). This might be explained by the enabling environment created by providing educational materials and other resources which could have motivated students.

We have found a significant difference in academic performance among students who attended private and public schools. Attending private school increased an average mark score of students as compared to their counterparts. This finding is in line with a study conducted in Northwest Ethiopia (40). Similarly, studies from Nigeria and India revealed that students who attended private schools scored better in reading, writing, and mathematics as compared to students from public schools $(41,42)$. This might be because private schools are better equipped in library and laboratory facilities than public schools. The monitoring and evaluation activities are perhaps tight in private schools. It might also be because students attending private school may also be from parents who are wealthier or have a higher educational level.

Limitations: This study is limited to schools in scope and the score used to assess the academic performance is also not from a standardized testing across the whole country. Thus, it might be difficult to extrapolate the proportion to the overall adolescent population in the country. We used a crosssectional data and the estimate might be better representative if a longitudinal follow-up data were used. We have only used anthropomorphic measurements to determine the nutritional status and did not assess the micronutrient status of study participants. Furthermore, the study did not assess IQ test due to lack of standardized testing systems in Ethiopia which is designed in the country context and culture appropriate enough to detect cognitive changes. We have no data on other covariates such as cigarette smoking and time devoted to physical exercise.

\section{Conclusions}


This study ascertained poor academic performance was reported among female sex adolescent students, students whose parents were separated and students of lowest wealth status households. Better nutritional status, particularly BAZ, seems to increase students' academic performance.

Wolaita Sodo town health office should design interventions targeted at improving adolescents' nutritional status. Microfinance institutions and other development and income-generating activities should target households with the lowest wealth status. Schools should give tutorial classes for all students, particularly girls, needing support to boost their academic score. We recommend further studies to determine the association of nutritional status with school performance by including the micronutrient status.

\section{Declarations}

Ethics approval and consent to participate

Ethical clearance was received from the ethical review committee at the College of Health Sciences and Medicine in Wolaita Sodo University in Ethiopia. The ethical clearance was written to the Wolaita zone Education department and we got permission from this department and its lower administrative structures to conduct the study. Finally, informed written consent was obtained from each participant, and parents/caregivers provided consent on behalf of students less than 18 years of age.

Consent to publish-Not applicable

\section{Availability of data and materials}

The datasets analyzed for this study are available with the corresponding author which can be accessed on reasonable request.

\section{Competing interests}

The authors declare that they have no competing interests.

\section{Funding}

This study was financially supported by South Ethiopia Network Universities in Public Health (SENUPH) project from the Norwegian Programme for Capacity Development in Higher Education and Research for Development (NORHED). The fund was facilitated by Wolaita Sodo University through a graduate-level research program. Neither of the parties had roles in the design, conduct, and decision to publish this research work.

\section{Authors' contributions}

SW conceived the study, designed the protocol, coordinated data collection, analyzed the data and interpreted findings, and drafted the manuscript. AA contributed to the design, analysis, and interpretation 
of the findings, and reviewed the manuscript. SK contributed to the design, analysis, interpretation of the findings, reviewed progressive drafts, and proofread the manuscript. All authors read and approved the final version of the manuscript.

\section{Acknowledgments}

We are grateful to SENUPH-NORHED for granting the study. We would also like to thank the School of Public Health at WSU for facilitating the research program. We acknowledge the Wolaita zone education department and local authorities for official permission. We are also grateful to the study participants for their consent to participate in the study. We acknowledge our responsible data collectors and supervisors.

\section{Abbreviations}

BAZ: BMI for Age Z-score; BMI: Body Mass Index; Cl: Confidence Interval; DDS: Dietary Diversity Score; FAO: Food and Agricultural Organization; HAZ: Height for Age Z-score; NGO: Non-Governmental Organization; NORHED: Norwegian Programme for Capacity Development in Higher Education and Research for Development; SD: Standard Deviation; SENUPH: South Ethiopia Network Universities in Public Health; TEM: Technical Error of Measurement; USA: United States of America; WHO: World Health Organization, WSU: Wolaita Sodo University

\section{References}

1. Jukes $M$, Drake L, Bundy D. School health, nutrition and education for all: levelling the playing field. Bull World Health Organ. 2009;87(1):75.

2. Mulugeta A, Hagos F, Stoecker B, Kruseman G, Linderhof V, Abraha Z, et al. Nutritional status of adolescent girls from rural communities of Tigray, Northern Ethiopia. Ethiopian Journal of Health Development. 2009;23(1):5-11.

3. Branigan A. (How) Does obesity harm academic performance? Stratification at the intersection of race, sex, and body size in elementary and high school. Sociology of Education. 2017;90(1).

4. WHO. Nutrition in adolescence: issues and challenges for the health sector: issues in adolescent health and development. In: Organization WH, editor. 2005.

5. Bisset S, Fournier M, Pagani L, Janosz M. Predicting academic and cognitive outcomes from weight status trajectories during childhood. International Journal of Obesity. 2013;37(1):154-9.

6. Sandjaja, Poh BK, Rojroonwasinkul N, Nyugen BKL, Budiman B, Ng LO, et al. Relationship between anthropometric indicators and cognitive performance in Southeast Asian school-aged children. British Journal of Nutrition. 2013;110:S57-S64.

7. WHO. Global Accelerated Action for the Health of Adolescents (AA-HA!): guidance to support country implementation. In: WHO, editor.

8. UNFPA. Status report adolescents and young people in sub-Saharan Africa: Opportunities and challenges. UNFPA; 2012. 
9. Prentice AM. The emerging epidemic of obesity in developing countries. International journal of Epidemiology. 2005;35(1):93-9.

10. NCD Risk Factor Collaboration (NCD-RisC). Worldwide trends in body-mass index, underweight, overweight, and obesity from 1975 to 2016 : a pooled analysis of 2416 population-based measurement studies in 128.9 million children, adolescents, and adults. Lancet. 2017;390(10113):2627-42.

11. Menezes IHCF, Neutzling MB, Carradezo JAdA. Risk factors for overweight and obesity in adolescents of a Brazilian University: a case-control study. Nutr Hosp. 2009;24(1):17-24.

12. Majgaard, Mingat $K$, Alain. Education in sub-Saharan Africa: A comparative analysis (English). In: Study AWB, editor. Washington, DC: World Bank Group; 2012.

13. The World Bank. Ethiopia general education quality improvement project II (P129828). The World Bank; 2017.

14. Garg R, Melanson S, Levin E. Educational aspirations of male and female adolescents from singleparent and two biological families: A comparison of influencial factors. Journal of Youth and Adolescence. 2006;36:1010-23.

15. Oyeromi SO, Olaolu FA, Fadocun JB, Omiyale GT. Effects of marital stability and divorce on the academic performance of adolescent students' in senior secondary schools in Ogun State, Nigeria. Greener Journal of Educational Research. 2018;8(4):94-100.

16. Usaini MI, Abubakar NB. The impact of parents' occupation on academic performance of secondary school students in Kuala Terengganu. Multilingual Academic Journal of Education and Social Sciences. 2015;3(1):112-20.

17. Farooq MS, Chaudhry AH, Shafiq M, Berhann G. Factors affecting students' quality of academic performance: A case of secondary school level. Journal of Quality and Technology Management. 2011;7(2):01-14.

18. Lillie M, Lema I, Kaaya S, Steinberg D, Baumgartner JN. Nutritional status among young adolescents attending primary school in Tanzania: contributions of mid-upper arm circumference (MUAC) for adolescent assessment. BMC Public Health. 2019;19(1):1582.

19. Adeomi AA, Adelusi IO, Adedeji PO, Awofeso AE, Oroleye OO, Gbadegesin DL. Nutritional status and Cardiometabolic health among adolescents; findings from southwestern Nigeria. BMC Nutrition. 2019;5(1):45.

20. Bhattarai S, Bhusal CK. Prevalence and associated factors of malnutrition among school going adolescents of Dang district, Nepal. AIMS Public Health. 2019;6(3):291-306.

21. Getahun Z, Jibat A. An assessment of factors that affecting academic performances of students': The case of Assosa general secondary and preparatory school, Ethiopia International Journal of African and Asian Studies. 2018;45:16-22.

22. CSA, ICF. Ethiopia Demographic and Health Survey 2016 Key Indicators Report. Addis Ababa, Ethiopia; Rockville, Maryland, USA: CSA, ICF; 2016. 
23. de Onis M, Onyango AW, Borghi E, Siyam A, Nishida C, Siekmann J. Development of a WHO growth reference for school-aged children and adolescents. Bull World Health Organ. 2007;85(9):660-7.

24. Asmare B, Taddele M, Berihun S, Wagnew F. Nutritional status and correlation with academic performance among primary school children, northwest Ethiopia. BMC Research Notes. 2018;11(1):805.

25. FAO. Dietary assessment: A resource guide to method selection and application in low resource settings. Rome2018.

26. FANTA. Nutrition Assessment, Counseling, and Support (NACS): A user's guide-Module2: Nutrition Assessment and Classification, Version 2. Washington DC: FHI 360/FANTA; 2016.

27. WHO. Anthro Plus for personal computers Manual: Software for assessing growth of the world's children and adolescents. Geneva: WHO; 2009.

28. Abebe F, Geleto A, Sena L, Hailu C. Predictors of academic performance with due focus on undernutrition among students attending primary schools of Hawa Gelan district, Southwest Ethiopia: a school based cross sectional study. BMC Nutrition. 2017;3(1):30.

29. Chikweru AE, Nweke AC. Effects of home background on educational development of secondary school students in Ebonyi state: A case study Onicha L.G.A. International Journal of Innovative Social \& Science Education Research. 2017;5(4):46-9.

30. Naik SR, Itagi SK, Patil M. Relationship between nutrition status, intelligence and academic performance of Lambani school children of Bellary district, Karnataka. International Journal of Farm Sciences. 2015;5(3):259-67.

31. Haile D, Nigatu D, Gashaw K, Demelash H. Height for age z score and cognitive function are associated with Academic performance among school children aged 8-11 years old. Arch Public Health. 2016;74(17):016-0129.

32. Wolde T, Belachew T. Chronic undernutrition (stunting) is detrimental to academic performance among primary schools of adolescent children: a randomized cross sectional survey in Southern Ethiopia. BMC Res Notes. 2019;12(1):019-4160.

33. Tasisa W, Tafesse T. Gender disparity in academic achievements in Ethiopian colleges of teacher education. International Journal of Social Science \& Education. 2013;3(1).

34. Wangu MJ. The impact of gender differences on student's academic performance in secondary schools in Ndumberi division, Kiambu, Kenya in Science subjects and languages 2014.

35. Joseph A, John O, Eric I, Yusuf S, Olubunmi A. Effect of gender on students' academic performance in computer studies in secondary schools in New Bussa, Borgu local government of Niger state. Journal of Education and Practice. 2015;6(33).

36. Ampofo ET. Determinants of academic performance among senior high school (SHS) students in the Ashanti Mampong manucipality of Ghana. European Journal of Research and Reflection in Educational Sciences. 2015;3(3):33-48.

37. Chalachew AA, Lakshmi VH. Assessing children academic achievement as correlates with parents' marital status: The case of Junior High school students in Addis Ababa. International Journal of 
Social Science \& Interdisciplinary Research. 2013;2(2):125-38.

38. Alubokin B, Akyina KO. Effects of divorce on the academic performance of some selected public senior high school students in the Bolgatanga municipality of Ghana. International Journal of Multidisciplinary Research and Development. 2015;2(10).

39. Eshetu AA. Parental Soci-economic status as a determinant factor of academic performance of students in regional examination: A case of Dessie town, Ethiopia. African Educational Research Journal. 2015;3(4):221-9.

40. Eshetu AA. Does school type matter in academic achievement in regional examination? Comparative study of private and government schools in Dessie administrative town, North Central Ethiopia. International Journal of Educational Studies. 2015;7(2).

41. Maliki AE, Ngban AN, Ibu JE. Analysis of Students' Performance in Junior Secondary School Mathematics Examination in Bayelsa State of Nigeria. Studies on Home and Community Science. 2009;3(2):131-4.

42. Gouda J, Das KC, Goli S, Pou LMA. Government versus private primary schools in India: An assessment of physical infrustructure, schooling costs and performance. International Journal of Sociology and Social Policy. 2013;33(11/12):708-24.

\section{Tables}

Table1 Socio-demographic and economic characteristics of the students and their parents involved in the study at Wolaita Sodo town in South Ethiopia, June 2019 


\begin{tabular}{|c|c|c|c|}
\hline Variables $(n=670)$ & & Frequency & Percentage \\
\hline Age in years & $10-14$ & 137 & 20.45 \\
\hline & $15-19$ & 533 & 79.55 \\
\hline Sex & Male & 331 & 49.40 \\
\hline & Female & 339 & 50.60 \\
\hline Current marital status of & Married & 545 & 81.34 \\
\hline parents & Separated & 125 & 18.66 \\
\hline Educational status of mothers & No formal education & 57 & 8.51 \\
\hline & Read and write & 134 & 20.00 \\
\hline & Primary & 123 & 18.36 \\
\hline & Secondary & 173 & 25.82 \\
\hline & College $\&$ above & 183 & 27.31 \\
\hline & No formal education & 21 & 3.13 \\
\hline Educational status of fathers & Read and write & 83 & 12.39 \\
\hline & Primary & 98 & 14.63 \\
\hline & Secondary & 150 & 22.39 \\
\hline & $\begin{array}{l}\text { College / university } \\
\text { completed }\end{array}$ & 318 & 47.46 \\
\hline & Farmer & 96 & 14.33 \\
\hline Occupational status of the & Merchant & 158 & 23.58 \\
\hline father & Government employer & 284 & 42.39 \\
\hline & Private & 115 & 17.16 \\
\hline & Daily laborer & 17 & 2.54 \\
\hline Occupational status of the & House wife & 205 & 30.60 \\
\hline mother & Merchant & 233 & 34.78 \\
\hline & Government employer & 158 & 23.58 \\
\hline & Private & 66 & 9.85 \\
\hline & Daily laborer & 8 & 1.19 \\
\hline Wealth quintile & Lowest & 110 & \\
\hline & Second & 136 & $\begin{array}{r}16.42 \\
20.30\end{array}$ \\
\hline & Middle & 136 & 20.30 \\
\hline & Fourth & 158 & 23.58 \\
\hline & Highest & 130 & 19.40 \\
\hline School type & Government & 444 & 66.27 \\
\hline & Private & 226 & 33.73 \\
\hline
\end{tabular}

Table2 Nutritional status, dietary diversity and behavioral characteristics of students involved in the study at Wolaita Sodo town in South Ethiopia, June 2019 


\begin{tabular}{lllc}
\hline Variables $(n=670)$ & & Frequency & Percentage \\
\hline Nutritional status (BAZ) & Thin & 42 & 6.27 \\
& Normal & 535 & 79.85 \\
& Overweight & 65 & 9.70 \\
& Obese & 28 & 4.18 \\
Dietary diversity & $>4$ & 274 & 40.90 \\
The purpose of spending time on the & $\leq 4$ & 396 & 59.10 \\
internet & For academic & 144 & 23.49 \\
& purpose & & \\
Alcohol consumption & For social media & 469 & 76.51 \\
& Yes & 166 & 24.78 \\
Absenteeism & No & 504 & 75.22 \\
& Yes & 163 & 24.33 \\
& No & 507 & 75.67 \\
\hline
\end{tabular}

Table 3 Relationship between nutritional indicators and academic performance of Adolescents in Wolaita Sodo town in South Ethiopia, June 2019

\begin{tabular}{lcc}
\hline Nutritional Indicators & \multicolumn{2}{c}{ Academic performance } \\
\cline { 2 - 3 } & Pearson coefficient (r) & P-value \\
\cline { 2 - 3 } Body mass index -for-age z- score (BAZ) & $0.2308^{*}$ & 0.01 \\
Height-for-age-z- score (HAZ) & $0.1373^{*}$ & 0.01 \\
\hline
\end{tabular}

* Correlation is significant at the 0.01 level (2-tailed).

Table 4 Predictors of Academic Performance of adolescents in Secondary school at Wolaita Sodo town in South Ethiopia, June 2019 


\begin{tabular}{|c|c|c|c|c|c|}
\hline \multirow[t]{2}{*}{ Variable $(n=670)$} & & \multicolumn{2}{|c|}{$\begin{array}{l}\text { Bivariate linear } \\
\text { regression }\end{array}$} & \multicolumn{2}{|c|}{$\begin{array}{l}\text { Multivariate linear } \\
\text { regression }\end{array}$} \\
\hline & & $\beta$ & $95 \%$ CI & $\beta$ & $95 \%$ CI \\
\hline Age & $15-19$ & 2.45 & $0.40,4.50$ & 1.44 & $-0.43,3.32$ \\
\hline 亏̄ex & Female & -1.97 & $\begin{array}{l}-3.62 \\
-0.32\end{array}$ & -2.63 & $-4.27,-0.98$ \\
\hline Marital status & Separated & -8.37 & $\begin{array}{l}-10.41 \\
-6.34\end{array}$ & -4.73 & $-6.73,-2.74$ \\
\hline \multirow[t]{4}{*}{ Education status of the mother } & $\begin{array}{l}\text { Read and } \\
\text { write }\end{array}$ & -2.92 & $\begin{array}{l}-4.98 \\
-0.85\end{array}$ & -1.74 & $-4.96,1.49$ \\
\hline & Primary & 0.30 & $-1.84,2.44$ & 0.29 & $-3.11,3.68$ \\
\hline & Secondary & 2.49 & $0.61,4.38$ & -0.19 & $-3.58,3.19$ \\
\hline & $\begin{array}{l}\text { College \& } \\
\text { above }\end{array}$ & 1.29 & $-0.57,3.15$ & -3.48 & $-7.28,0.32$ \\
\hline \multirow[t]{4}{*}{ Education status of the father } & $\begin{array}{l}\text { No formal } \\
\text { education }\end{array}$ & -1.37 & $-6.13,3.39$ & 2.50 & $-2.33,7.34$ \\
\hline & $\begin{array}{l}\text { Read and } \\
\text { write }\end{array}$ & -3.60 & $\begin{array}{l}-6.11 \\
-1.10\end{array}$ & 1.48 & $-1.38,4.34$ \\
\hline & Primary & -1.22 & $-3.57,1.12$ & 0.79 & $-1.66,3.22$ \\
\hline & Secondary & 0.17 & $-1.82,2.16$ & -0.09 & $-2.14,1.94$ \\
\hline \multirow[t]{4}{*}{ Jccupational status of Mother } & Housewife & -1.24 & $-3.04,0.55$ & 0.49 & $-2.11,3.10$ \\
\hline & Merchant & -0.36 & $-2.10,1.38$ & -0.01 & $-2.44,2.43$ \\
\hline & $\begin{array}{l}\text { Private } \\
\text { employee }\end{array}$ & 0.93 & $-1.85,3.71$ & 0.41 & $-2.38,3.21$ \\
\hline & $\begin{array}{l}\text { Daily } \\
\text { labourer }\end{array}$ & -5.10 & $\begin{array}{l}-12.73 \\
2.53\end{array}$ & 1.83 & $-5.61,9.27$ \\
\hline \multirow[t]{4}{*}{ Wealth index } & First-class & -10.66 & $\begin{array}{l}-12.7 \\
-8.57\end{array}$ & -9.92 & $-12.79,-7.04$ \\
\hline & Second class & -4.11 & $\begin{array}{l}-6.15 \\
-2.08\end{array}$ & -5.66 & $-8.13,-3.19$ \\
\hline & Middle class & 2.19 & $0.14,4.25$ & -1.80 & $-4.08,0.48$ \\
\hline & Fourth class & 4.22 & $2.20,6.24$ & -0.62 & $-2.88,1.64$ \\
\hline School type & Private & 5.83 & $4.13,7.52$ & 4.18 & $2.46,5.90$ \\
\hline $\begin{array}{l}\text { Гhe purpose of spending time } \\
\text { on the internet }\end{array}$ & $\begin{array}{l}\text { For social } \\
\text { media }\end{array}$ & -2.71 & $\begin{array}{l}-4.76 \\
-0.67\end{array}$ & -1.40 & $-3.23,0.42$ \\
\hline Alcohol consumption & No & 1.79 & $-0.13,3.70$ & -0.03 & $-1.77,1.72$ \\
\hline JDS & Adequate & 3.56 & $1.89,5.22$ & 1.01 & $-0.56,2.64$ \\
\hline \multirow[t]{2}{*}{ Nutritional status } & $\mathrm{BAZ}$ & 2.14 & $1.46,2.83$ & 1.89 & $1.14,2.64$ \\
\hline & HAZ & 1.33 & $0.60,2.05$ & 1.48 & $0.72,2.24$ \\
\hline
\end{tabular}


Page 16/16 